\title{
0 Estado Federativo de cooperação e as políticas de municipalização do ensino: limites e potenciais
}

Sonia Martins de Almeida Nogueira* Juliano Soares Rangel"

\section{Resumo}

A municipalização do ensino emerge como diretriz política adotada pelo Brasil em sua identidade de Estado Federativo de caráter cooperativo, em decorrência de políticas internacionais em sua abrangência e afirmação do sistema neoliberal-capitalista, da globalização, da inserção na Constituição Federal de 1988, da distribuição de competências entre os entes federativos, dos princípios da gestão democrática do ensino público e da colaboração reciproca. Este ensaio tem como objetivo delinear como se desenvolve o processo político de municipalização, apontando seus limites e potenciais no que se refere à política educacional no Brasil, a partir de uma abordagem dos efeitos de políticas traçadas na legislação constitucional e infraconstitucional, caracterizados em tais documentos como favoráveis ao desenvolvimento de uma nação identificada pela diversidade econômica, política e social.

Palavras-chave: Federalismo. Descentralização. Gestão democrática. Municipalização do sistema de ensino.

\section{The Federal State of cooperation and the municipalization of the educational system: limitations and potentials \\ Abstract}

The municipalization of education emerges as a policy guideline adopted by Brazil in its identity as a Federal State of cooperative character, due to the political and international in-scope affirmation of the neo-liberal capitalist globalization, of

\footnotetext{
* Doutora em Educação, Universidade Federal do Rio de Janeiro (UFRJ); Professora do Programa de PósGraduação em Políticas Sociais, Universidade Estadual do Norte Fluminense Darcy Ribeiro (UENF). E-mail: nogueira@uenf.br

** Mestrando do Programa de Pós-Graduação em Políticas Sociais, UENF. E-mail: juliano.s.rangel@gmail.com
} 
the insertion of the 1988 Federal Constitution, the distribution of powers among the federal entities, the principles of democratic management of public education and mutual cooperation. This essay aims to sketch how the political process of municipalization is developed, indicating its limitations and potentials within the educational policy in Brazil, leading off from an approach to the political effects of the constitutional and infraconstitutional legislation, favoring the development of a nation characterized by its social, political and economic diversity.

Keywords: Federalism. Decentralization. Democratic management. The municipalization of the educational system.

\section{El Estado Federativo de cooperación y las politicas de municipalización de la enseñanza: limites y potencialidades Resumen}

La municipalización de la enseñanza emerge como directriz política que Brasil adoptó en su identidad de Estado Federativo de carácter cooperativo, como consecuencia de politicas internacionales en su amplitud y afirmación del sistema neoliberal-capitalista, de la globalización, de la inserción en la Constitución Federal de 1988, de la distribución de competencias entre las entidades federativas, de los principios de la gestión democrática de la enseñanza pública y de la colaboración recíproca. Este ensayo tiene por objeto delinear el desarrollo del proceso político de municipalización, señalar sus límites y potencialidades referentes a la política educacional brasileña, a partir de un abordaje de los efectos de políticas orientadas en la legislación constitucional e Infraconstitucional, caracterizados en tales documentos como favorables al desarrollo de una nación identificada por su diversidad económica, politica y social.

Palabras clave: Federalismo. Descentralización. Gestión democrática. Municipalización del sistema de enseñanza.

\section{Introdução}

A discussão acerca das políticas de municipalização adotadas pelo Brasil traz para a arena, em decorrência da análise do processo de descentralização de competências e distribuição de atribuições entre os entes federativos pela Constituição Federal (BRASIL, 1988), os princípios da colaboração reciproca e da gestão democrática da educação, não se podendo olvidar a articulação da descentralização como pressuposto da gestão democrática no modelo da reforma educacional, esta decorrente do cenário da economia mundial, fator resultante da globalização e do sistema neoliberal-capitalista.

A década de 1980 no Brasil é apontada como tendo sido o palco político-temporal da mobilização da sociedade civil em torno de objetivos comuns, objetivos coletivos que almejaram a reafirmação da obrigação do Estado para com as politi- 
cas sociais, num quase retorno à proposta do Welfare State, bem como palco de atuação suprema da sociedade civil na cobrança por seu espaço no campo da política. Esse período estivera marcado por traços de organização e resistência, resgate e respeito aos direitos humanos e preocupação com o meio ambiente e a qualidade de vida por parte da sociedade civil organizada (SANDER, 2005, p. 101).

Com a promulgação da Carta Magna (BRASIL, 1988), o Estado, sob a pressão da sociedade, organizou-se de forma diversa: o federalismo, que anteriormente se manifestara em seus tipos centrífugo (Velha República, entre 1898-1930) e centrípeto (1930-1980), ganha o caráter de cooperação. Cury (2006, p. 115) expõe que:

[...] o federalismo de cooperação busca um equilibrio de poderes entre a União e os Estados membros, estabelecendo laços de colaboração na distribuição de múltiplas competências por meio de atividades planejadas e articuladas entre si, objetivando fins comuns. Esse federalismo político é o registro jurídico de nossa atual Constituição.

0 tipo de federalismo por cooperação per si indica a adoção da Lei-Mor do princípio da colaboração recíproca entre os entes federativos e, de certo, como se levanta a temática colaboração se torna fácil deduzir a descentralização de competências por parte do Estado. Convém acentuar que o artigo 18, que se refere à organização político-administrativa, confere autonomia a todos os entes federativos.

Assim, as competências são distribuídas em consonância com o artigo 23, que estabelece a competência comum, na qual se reconhece a necessidade da cooperação e colaboração entre estes entes e sociedade civil para o progresso da nação e que determina que as responsabilidades sejam assumidas de forma conjunta. Assim, o Estado brasileiro adota a prática de descentralização das políticas.

0 caráter da descentralização ficara evidenciado no campo da política educacional com a disposição constitucional do art. 206, inciso VI, que prevê como princípio a gestão democrática do ensino público. Esse artigo expressa a responsabilidade e a necessidade da cooperação por parte da sociedade civil na gestão escolar. Valhe lembrar que o art. 205 da referida Lei (BRASIL, 1988) institui a Educação como um direito de todos, sendo dever do Estado e da familia promovê-la e incentivá-la com a colaboração da sociedade, percebendo-se, desde então, a busca pela legitimação de uma sociedade civil comprometida, que deve se posicionar, necessariamente, de "mãos dadas" com o Estado para assegurar o exercício desse direito.

Cabe aqui uma digressão que situe a Constituição como lei fundamental da nação, constituindo "uma força ativa e eficaz que informa todas as leis e institui- 
ções jurídicas vigentes" (LASALLE, 1985, p. 11). Assim, seu texto estabelece as diretrizes da ação política dos entes federativos, pois "não se pode decretar [...] outras leis contrárias à fundamental" (LASALLE, 1985, p. 11).

Se a Carta Magna (BRASIL, 1988) é apontada como fator interno de inserção da descentralização, não menos há que se destacar os fatores externos que propiciaram a instituição desses princípios norteadores, quais sejam, o sistema neoliberal-capitalista e o processo de globalização, fatores que fazem o Estado pender para uma postura de minimização, em contraposição à maximização do mercado e à minoração de despesas com políticas sociais e captação de recursos, a fim de fortalecer uma receita que seja contributiva e competitiva face ao cenário global; trata-se do momento em que o Estado passa por um striptease: é a relativização da soberania nacional em detrimento de uma transnacional. Esta é a argumentação de Bauman (1999, p. 74):

[...] no cabaré da globalização,o Estado passa por um striptease e no final do espetáculo é deixado apenas com as necessidades básicas: seu poder de repressão. Com sua base material destruida, sua soberania e independência anuladas, sua classe política apagada, a nação-estado torna-se um mero serviço de segurança para as mega-empresas.

As políticas de municipalização do ensino, nesse contexto, são visualizadas como uma das formas de descentralização política, razão pela qual merece destaque. Acrescente-se que, por se estabelecer no plano local, a municipalização do ensino pode permitir ao espectador perceber de forma mais nítida os efeitos decorridos da descentralização instituída pela Carta Magna (BRASIL, 1988). Assim, a proposta de municipalização deve identificar-se com o princípio de descentralização, representando uma questão política fundamental para assegurar a participação da comunidade, caracterizando um processo de negociação gradativa e contingencial.

Entende-se, vale acentuar, que descentralização não se lê como "prefeiturização", nem tampouco como "desconcentração". No entanto, considerada a ênfase na municipalização do ensino, o discurso de democratização encontrou oposição significativa gerada pelo paternalismo como modelo político preponderante em muitas prefeituras e seu consequente não comprometimento com a democratização.

Esta argumentação poderia ser ampliada pela abordagem das questões da ingerência do Estado e da análise das relações entre o nacional e o local. 0 processo histórico de reorganização do Estado brasileiro, de seu modelo jurídico político, pós regime militar instaurado em 1964, pode ser descrito pela análise de Werle (2005, p. 28): "O Estado constantemente remodela, redefine, homogeneiza suas numerosas estruturas e instâncias e as recoloca sob o prisma de uma nova divisão de poder tendo em vista a unidade nacional". 
0 Estado nas sociedades democráticas representa os interesses de toda a sociedade e, em seu modelo, constitui e regulamenta o público e o privado. Na abordagem da organização dos sistemas de ensino, apesar do regime de cooperação instituído em 1988, a União, os Estados e os Municípios permanecem no campo das relações de forças e tensões entre suas estruturas e instâncias diversas, inconsistências, vinculação a interesses de diferentes grupos e outros fatores (WERLE, 2005; NOGUEIRA, 2004; SANDER, 2005). Este cenário permitiria ampliar o escopo deste estudo para abranger a questão da ingerência do Estado, fragilizando o poder local, e da permeabilidade entre essas instâncias de poder. Não é este, entretanto, o foco da discussão, permanecendo estas considerações como uma digressão.

\section{Fatores de impulsão à descentralização: a questão da política educacional}

A mundialização ditada em recomendações pelo Fundo Monetário Internacional e pelo Banco Mundial estimulou a política econômica a se concentrar no crescimento das exportações, na redução da demanda interna e em certo número de restrições orçamentárias e em algumas privatizações (CARNOY, 2003, p. 70).

Na década de 1970, o endividamento dos paises em desenvolvimento e a ineficácia do serviço público deram ênfase a uma visão oriunda de países hegemônicos sobre a maneira como as economias em crise deveriam se reorganizar para recuperarem o caminho do crescimento. Por sua vez, a aplicação das politicas traçadas culminou com o aumento efetivo das disparidades econômicas e da situação de miséria, o declínio do papel do Estado no crescimento econômico e redução do financiamento dos serviços públicos, principalmente, na Educação (CARNOY, 2003, 2004).

Com o traçado dos ditames da mundialização, passa a ser considerado necessário o entendimento pelos decisores no campo da política educacional, no Brasil e nos demais paises em desenvolvimento, de que o Estado, por se encontrar num momento de dificuldade financeira profunda, deve restringir seus investimentos em políticas sociais e o investimento privado no campo educacional mostra-se como sendo a melhor alternativa.

No que se refere ao aparato estatal, Therborn (2001, p. 83) destaca no neoliberalismo traçados de prevalência do processo de mercantilização do Estado, de desburocratização e de destecnocratização, que deixam lugar a novos mecanismos de gerência derivados de dinâmicas de mercado. 0 Fundo Monetário Internacional (FMI) e o Banco Mundial recomendam a adoção de restrições orçamentárias, que se aliam à ênfase em torno da redução dos serviços públicos, a descentralização de competência por parte da União ganha apoio internacional, bem como é recomendada e catalogada como uma reforma que aumenta a produtividade da Educação. 
No cenário mundial, nos anos 1980 e 1990, as instituições que promoviam o atendimento às concepções éticas, redistribuição de renda, fomento da solidariedade e atendimento das necessidades sociais perderam importância e legitimidade. Passouse a cotejar instituições que incentivassem competências ou méritos que pudessem ser exercidos no mercado. Assim, os modelos e instrumentos de políticas sociais se deslocaram e hoje apontam enfaticamente em direção à responsabilidade própria do individuo e do seu posicionamento no mercado (SOBOTKA, 2006, p. 80).

0 que se vivencia é o modelo sistêmico neoliberal-capitalista em que os Estados se mostram atrelados às políticas de mercado, no plano global, de controle perdido: "ninguém parece estar no controle agora. Pior ainda, não está claro o que seria nas circunstâncias atuais 'ter o controle'" (BAUMAN, 1999, p. 66). Ressalta-se que não se trata da negação da existência do Estado, mas de sua redução a mero manipulador de recursos e de gerenciamento de políticas, em que o Estado Nação tem relativizada a sua soberania face às forças erosivas transnacionais'.

Nesse contexto, em Sander (2005, p.107), a descentralização mostra-se como sendo decorrente de um sistema maior em que estão inseridas as nações, uma aldeia global balizada pelo sistema neoliberal-capitalista. E, no campo educacional são sentidos, de forma tortuosa, todos os efeitos não desejáveis da mundialização, o que conduz Carnoy $(2003$, p. 85) ao pensamento de que a mundialização entra no setor da educação montada em um "cavalo ideológico" e suas repercussões sobre o ensino e a produção de conhecimento são amplamente o fruto do liberalismo motivado pelo dinheiro e não por uma visão clara em relação ao aprimoramento da Educação.

Já em início dos anos de 1990, em Jomtien, na Tailândia, na esfera educacional, fora desenvolvida a Declaração Mundial sobre Educação para Todos: plano de ação para satisfazer as necessidades básicas da aprendizagem, documento movido pelas grandes transformações em curso e orientado pelas mudanças sociais e culturais em países industrializados ou em desenvolvimento. Podendo ser apontada como recomendações no campo da política educacional das nações desenvolvidas às menos desenvolvidas, ou em processo de industrialização tardio, a Declaração é objeto de análise por Silva Júnior (2004, p. 70-75), que desvela o fato de que esta trouxera em seu bojo recomendações aos países para a aplicabilidade no campo educacional,

\footnotetext{
1 Termo empregado por G. H. Von Wright (apud BAUMAN, 1999, p. 64) ao analisar que, no processo de globalização, o capital não tem domicílio fixo e os fluxos financeiros estão bem além do controle dos governos nacionais, onde muitas das alavancas da política econômica não mais funcionam; assim, aponta o fato de que “a nação-estado parece que está se desgastando ou talvez 'definhando'[...] As forças erosivas são transnacionais. Uma vez que as nações-estados continuam sendo as únicas estruturas para um balanço e as únicas fontes de iniciativa política efetiva, a 'transnacionalidade' das forças erosivas coloca-as fora do reino da ação deliberada, proposital e potencialmente racional. Como tudo o que elide essa ação, tais forças, suas formas e ações são ofuscadas na névoa do mistério; são objetos de adivinhação e não de análise confiável [...]”. da participação; essas dimensões conectam-se, interpenetram-se e complementam-se.
} 
recomendações estas que podem ser entendidas como suporte do processo de privatização e descentralização do ensino. Atenta-se, no entanto, para as iniciativas da Organização das Nações Unidas (ONU) nos anos 1990, buscando dar uma nova ênfase ao desenvolvimento social, requisitando a participação e o suporte de toda a sociedade civil. Foram organizados vários eventos mundiais, perseguindo estabelecer uma ampla política consensual voltada para o desenvolvimento humano, em particular do desenvolvimento social.

Assim, ocorreram múltiplas iniciativas que foram agenda com o foco central em preocupações de ordem social, buscando uma "cultura de desenvolvimento", com cinco dimensões interrelacionadas: paz, crescimento econômico, proteção do meio ambiente, condições sociais de saúde e democracia. Nesse decênio, a educação, desde Jomtien, foi percebida como fator primordial na análise das questões de pobreza absoluta, fome, doença e analfabetismo (ORGANIZACIÓN DE LAS NACIONES UNIDAS, 1997).

É relevante atentar que, no entanto, desde os anos 1970, o desenvolvimento econômico como tese parecia disassociar-se do desenvolvimento social, à luz das diretrizes do FMl e do Banco Mundial. A crise econômica dessa década, a reorganização das relações internacionais no campo do mercado e a releitura do capitalismo nas teses neoliberais emergentes, entre outros fatores, redesenharam, ao longo das três últimas décadas do século XX, o sistema econômico e suas interrelações com o sistema político.

Cabe acentuar que, no Brasil, a partir da década de 1980, a questão educacional, antes de ser uma proposição ligada ao crescimento econômico, passou a ser uma questão política no momento em que as instituições autoritárias, que caracterizavam o modelo político do regime militar, foram sendo denunciadas e uma concepção de direitos de cidadania coloca em questão a atuação do Estado (BRITO, 2003).

No período dos anos 1980, se redefiniram as relações entre Estado e sociedade civil, dada a pressão dos movimentos sociais por projetos 'inovadores' em que o Estado assumisse, tomasse para si a responsabilidade quanto às políticas sociais, numa tentativa de reafirmação do modelo do Welfare State.

Assim, a década de 1980 mostrou-se como o palco político-temporal das inovações, o momento em que a sociedade civil se organizou e clamou pela postura de um Estado presente e operante, o momento em que a sociedade evocou a instauração de um Estado democrático e legítimo.

No contexto apontado, a Constituição Federal de 1988 optou por um federalismo cooperativo sob a denominação de regime de colaboração recíproca, descentralizado, com funções compartilhadas entre os entes federativos (CURY, 2006, p. 121), valendo-se do fato de que a descentralização estabelecida na Carta Magna nada mais expressava do que 
a necessidade da União de compartilhar responsabilidades e, simultaneamente, comprometer em menor proporção sua receita com a politica educacional. Esse foi, ainda, o momento em que o Estado aproveitou a oportunidade para compartilhar suas responsabilidades também com a sociedade civil, legitimando assim a participação social e cidadã ${ }^{2}$ Em Gohn (2004 apud GUIMARÃES, 2006), a participação cidadã pode ser compreendida como o direito dos cidadãos organizados de participar das discussões e dos processos decisórios nos assuntos de interesse público; a participação seria aquela lastreada no conceito de cultura cívica e capital social. Em Jacobi (2002 apud GUIMARÃES, 2006), a participação social é o momento do fortalecimento e busca de um desenvolvimento autônomo; é aquela que coloca a sociedade em contato com o Estado. Ambas se referem à institucionalização. Isto o fez ao estabelecer, no art. 205 da Constituição Federal (BRASIL, 1988), a Educação como direito de todos e dever do Estado e da família e com colaboração da sociedade em seu incentivo e promoção e ao estabelecer como princípio a reger 0 ensino o da gestão democrática do ensino público, em seu art. 206, inciso Vl.

Neste cenário, é preciso acentuar o ponto de partida que está nos princípios da indissolubilidade da união dos entes federativos e da colaboração recíproca, afirmados na Carta Magna (BRASIL, 1988) em seus arts. $1^{\circ}, 18,23$ e $60, \S 4^{\circ}, \mathrm{I} .0$ que se percebe, é que a União estabeleceu um sistema de repartição de competências entre os entes federativos, evidenciando, por conseguinte, a adoção do processo de descentralização de políticas.

A Constituição faz uma escolha por um regime normativo e político, plural e descentralizado, no qual se cruzam novos mecanismos de participação social com um modelo institucional cooperativo que amplia o número de sujeitos políticos capazes de tomar decisões. Por isso mesmo, a cooperação exige entendimento mútuo entre os entes federativos e a participação supõe a abertura de novas arenas públicas de deliberação e mesmo de decisão (CURY, 2006, p. 121-122). E, da mesma forma que a Lei-Mor institui e reparte competências entre os entes federativos, faz imperar sobre os mesmos o regime da colaboração mútua/ reciproca.

Importante frisar que a necessidade descentralizadora do Estado, bem como da unidade nacional, é evidenciada por juristas como princípio norteador existente desde a Constituição Republicana de 1891, conforme aduz Moraes (2007, p. 254): "O princípio da indissolubilidade em nosso Estado Federal foi consagrado em nossas constituições republicanas desde 1891 (art. 1º) e tem duas finalidades básicas: a unidade nacional e a necessidade descentralizadora".

2 Em Gohn (2004 apud GUIMARÃES, 2006), a participação cidadã pode ser compreendida como o direito dos cidadãos organizados de participar das discussões e dos processos decisórios nos assuntos de interesse público; a participação seria aquela lastreada no conceito de cultura cívica e capital social. Em Jacobi (2002 apud GUIMARÃES, 2006), a participação social é o momento do fortalecimento e busca de um desenvolvimento autônomo; é aquela que coloca a sociedade em contato com o Estado. Ambas se referem à institucionalização da participação; essas dimensões conectam-se, interpenetram-se e complementam-se. 
0 regime de colaboração, acentue-se, se mostra um processo moroso, em especial no que tange ao federalismo alcançado no Brasil que, segundo Cury (2006), sofre ante: à omissão de parlamentares, a despeito do que estabelece a Constituição Federal (BRASIL, 1988), em seu art. 23, parágrafo único; ao federalismo competitivo, guerra fiscal entre Estados e Municípios e Distrito Federal; à representação política reduzida a número de eleitores e à desigualdade social de que está acometida a nação. Diante deste quadro, dáse ênfase à urgência de fortalecer os princípios da indissolubilidade e da colaboração recíproca, que definem o Brasil como sendo um Estado Federativo de Cooperação.

Neste ponto, é necessário pôr em foco o princípio da autonomia, que se apresenta como corolário da organização federativa, uma vez que a federação importa uma só entidade soberana, com entidades federadas que, de acordo com Cury (2006, p.114): "[...] gozam de autonomia, cuja relatividade se dá dentro dos limites jurisdicionais atribuídos e especificados. Daí que tais subunidades não são nem nações independentes nem somente unidades administrativas".

Trata-se, pois, de um regime em que os poderes de governo são repartidos entre instâncias governamentais por meio de campos de competências legalmente definidas.

Sublinha-se que, no campo da política educacional, a descentralização se estabelece com a disposição da Constituição Federal (BRASIL, 1988), em seus arts. 211 e 212, ao repartir as competências e adotar o regime de colaboração em relação aos entes federativos.

A legitimação da participação da sociedade pela Constituição Federal (BRASIL, 1988) ganha a denominação de 'princípio da responsabilidade coletiva', princípio assim designado ante a função dada à sociedade civil pelo Estado. 0 ideal democrático proposto pela Constituição Federal é de cidadãos voltados para a evolução da coisa pública (dos bens, dos deveres e garantias fundamentais), informados dos acontecimentos socioeconômicos e políticos, dos principais problemas, capazes de escolher entre as diversas alternativas apresentadas pelas forças políticas e fortemente interessados em formas diretas ou indiretas de participação. Pode-se argumentar que a maior inovação constitucional se procedeu com a legitimação da participação da sociedade no campo da prática política, presente nos dispositivos constitucionais dos artigos 205 e 206 (BRASIL, 1988).

\section{0 princípio da gestão democrática do sistema de ensino público}

A gestão democrática da educação, com suporte nos princípios de descentralização e de autonomia, é um valor já consagrado no Brasil e no mundo, embora ainda não totalmente compreendido e incorporado à prática social global e à prática educacional brasileira, sendo indubitável sua importância como um recurso de participação humana e de formação para a cidadania (FERREIRA, 2000). Prevista 
pela Constituição Federal (BRASIL, 1988), a gestão democrática da educação é adotada como diretriz de política pública educacional pelo Estado a ser compreendida em sua função estratégica, na medida em que o seu alcance é considerado um mecanismo para o atendimento das demais diretrizes (MENDONÇA, 2001). Essa garantia foi inegavelmente marcante forma da materialização na dinâmica social, na luta pela democratização da educação no Brasil.

Ao instituir a gestão democrática do ensino público, o documento legal inseriu a sociedade civil no cenário, dessa vez, não mais como coadjuvante do processo de formação histórico-política do país, mas como protagonista, importando, necessariamente, o princípio de participação.

Como atingir essa gestão democrática? Realmente, não se mostra tarefa fácil. E a dificuldade é traçada por Ferreira e Aguiar (apud CURY, 2006), ao apontar que a gestão democrática somente o é mediante uma prática que articule a participação de todos, o desempenho administrativo-pedagógico e o compromisso sociopolítico. Acrescenta-se que, mesmo que legalmente a gestão democrática não atinja o setor privado, o caráter ético e axiológico da democracia paira sobre todas as instituições escolares ao repudiar todas as formas de autoritarismo.

0 que deve por ora ser bem definido é o fato de que, com o advento da Constituição Federal (BRASIL, 1988), a educação se torna política pública de oferta devida pelo Estado para a efetivação do direito à educação, demandando a colaboração da sociedade na sua promoção e incentivo. Assim, a Educação deve atingir a todos os cidadãos de forma indiscriminada, seja no quantitativo de vagas ofertadas, seja ainda na qualidade enquanto compromisso de uma educação que gere frutos positivos à construção da cidadania.

\section{As políticas de municipalização do sistema de ensino no Brasil: limites e potenciais}

A ideia de municipalização do ensino, uma das formas de descentralização política, no Brasil parte de Anísio Teixeira já no século XX, uma ideia associada à doutrina política e social da Constituição de 1946.

Num traçado do processo de centralização/descentralização das políticas educacionais no Brasil, Libâneo, Oliveira e Toschi (2003, p. 135-136) apontam que o escolanovista Anísio Teixeira foi o ardoroso defensor da descentralização por meio do mecanismo de municipalização. Para Anísio Teixeira, a descentralização educacional contribuiria para a democracia e para a sociedade industrial, moderna e plenamente desenvolvida. 0 eminente educador acreditava que a municipalização do ensino primário constituiria uma reforma política, isto é, significaria reconhecer a maioridade dos municípios e discutir a necessidade de democratização e de descentralização do poder político no país. 
Nos anos 1970, foi editada a Lei 5.692 (BRASIL, 1971), que estabeleceu o ensino fundamental ( $1{ }^{\circ} \mathrm{Grau}$ ) de oito anos letivos, o que ampliou a responsabilidade dos governos municipais, sem que o Poder Central oferecesse recursos financeiros diretamente aos municípios. Caberia a estes acrescentarem recursos próprios. Quanto à assistência técnica, esta atenderia os sistemas estaduais de ensino (BRASIL, 1988). Vigorava um regime federativo centrípeto, em que não se reconhecia a existência administrativa dos municipios.

Inobstante a transição democrática já observada ao final dos anos 1970, nesse período não se podia perceber nos municípios as mudanças ocorridas nos Estados membros. Assim sendo, o pensamento que passou a dominar era o de que as mudanças democráticas deveriam ocorrer dos niveis federal e estadual para o municipal, pois somente por essa via se tornaria efetivo o processo de descentralização.

Com a Constituição da República Federativa do Brasil, promulgada em 05 de outubro de 1988, é que o município se legitimou como instância administrativa e a responsabilidade do ensino fundamental Ihe foi repassada prioritariamente. 0 referido diploma legal, mais a Lei de Diretrizes e Bases da Educação Nacional (LDBEN) (BRASIL, 1996b), possibilitaram ao município a instituição, planejamento, organização e gestão de seu próprio sistema de ensino (BRASIL, 1988, 19966).

0 que se observa é que a descentralização do poder, a autonomia e a gestão democrática do sistema de ensino público, desde 1988, são alicerces que sustentam a atuação dos Municípios. E o campo normativo, através dos dispositivos legais acima expostos, mais a Emenda Constitucional n¹4 (BRASIL, 1996a), a Lei no 9.424 (BRASIL, 1996c) e o Decreto $n^{\circ} 2.264$ (BRASIL, 1997), em muito fortaleceram a descentralização do ensino. Assim, os referidos diplomas definiram o papel dos municípios, como ente federativo autônomo, na questão da formulação e da gestão da política educacional, com a criação de seu próprio sistema de ensino, ao mesmo tempo em que esses mesmos diplomas definiram, de forma clara, a colaboração e parceria entre a União, os Estados e os Municípios como sendo a postura mais apropriada para a procura de uma educação de qualidade social.

Os instrumentos normativos mencionados reconhecem a autonomia dos municípios para com o sistema de ensino, o que quer dizer que o sistema de ensino no país passa a ser não mais nacional, contrapondo-se ao fato de que a Educação, sim, é nacional, conforme destaca Cury (2006, p. 124).

As políticas de municipalização levantam um debate acirrado entre os seus defensores e não defensores, em que, ante a complexidade, faz pesar o enfrentamento entre duas posturas compreensiveis de pensamento, ponderações, limites e potencialidades da prática destas políticas. 0 debate mostra-se muito bem expresso na exposição de Carnoy (2003), que este estudo referenda em análise. A abordagem 
da municipalização do ensino nos permite indagar com Davies (1992) se ela é um fator de democratização e de valoração da cultura local. 0 autor comenta que é preciso haver uma identificação social e política entre governantes e governados.

0 argumento levantado em favor da municipalização é o de que as escolas usufruem de uma autonomia mais ampla em matéria de educação, incumbindo às coletividades locais, ao corpo docente e aos próprios diretores de estabelecimento 0 controle local dos programas escolares e dos métodos de ensino.

Destaca Martins $(2004$, p. 14) que se supõe que a democracia exercida em escala menor, nas localidades, facilite a superação dos problemas postos pelos diferentes niveis de burocracia, bem como pela complexa questão da representação; desta forma, nas cidades as condições para o desenvolvimento de experiências alternativas e o exercício de práticas democráticas seriam maiores, estariam delimitadas territorialmente, se beneficiariam da proximidade do poder e seriam baseadas na criatividade dos atores locais, idéia que encontra respaldo nas teorias contra-hegemônicas de democracia que também defendem uma convivência e uma complementariedade entre niveis de escala dentro do regime democrático (SANTOS; AVRITZER apud MARTINS, 2004, p. 14).

Segundo o autor, o ensino será de melhor qualidade se as autoridades educativas locais se sentirem, e forem julgadas, responsáveis pelas tarefas educativas, razão pela qual a municipalização, enquanto uma forma de descentralização, estar catalogada como uma reforma que aumenta a produtividade da Educação e, por isso mesmo, contribui de maneira significativa no que tange ao aperfeiçoamento da qualidade dos recursos humanos de uma nação, respondendo melhor aos responsáveis dos educandos e conferindo às autoridades locais uma maior autonomia de decisão no campo educacional. Com a ênfase na gestão local e na autonomia das escolas no campo financeiro, os pais sentir-se-iam mais envolvidos, os professores trabalhariam melhor com aprimoramento da qualidade do ensino e melhoria na exploração dos recursos disponíveis. Esses defensores citam como modelo de gestão as escolas privadas que teriam o sucesso garantido por estes fatores.

Como embate às ideias defendidas por esse grupo, subsiste argumento de que nada comprova verdadeiramente que a descentralização da gestão e do financiamento de sistemas educativos favoreça a inovação e a eficácia dos métodos pedagógicos e a educação mais qualificada. Carnoy (2003) destaca este argumento ao fazer menção ao modelo implementado pelos Estados Unidos, que, tendo adotado a forma de autonomia das escolas, nenhuma melhoria notória trouxe ao seu sistema de ensino, acentuando que o resultado mais corrente é a carência de professores, ou a decisão de não ensinar o que se encontra no programa ou, ainda, não respeitar o número diário de horas do curso. A descentralização, que visa reforçar o controle exercido pela comunidade sobre os professores, os torna diretamente responsáveis perante os pais de alunos, o que possibilita a ilação de que um controle mais estreito pode estimular a produtividade, mas não necessariamente a inovação. 
Ainda em Carnoy (2003) encontramos argumentos relevantes nas análises que expõem a gestão descentralizada, mostrando claramente que a transferência de atribuições, associada a um crescimento mais lento ou ajuda monetária e tecnológica limitada por parte da administração central às escolas autônomas e públicas, pode alcançar objetivos financeiros, mas tem tendência a reforçar a desigualdade do desempenho entre Estados e municipalidades mais pobres e os mais ricos, o que atesta a necessidade da direção por uma autoridade central que injete os recursos de forma isonômica, respeitando as diferenças, tratando os iguais de forma igual e os desiguais de forma desigual.

Os autores abordados por Carnoy $(2003,2004)$ defendem que a descentralização e a autonomia escolar podem aprimorar a qualidade da educação no plano local, mas, em geral, unicamente nos casos em que os gastos com a educação e a competência técnica do poder central são reforçados e, num sentido particular, em relação às localidades mais desfavorecidas e às escolas com renda mais baixa que não dispuserem de recursos humanos, financeiros ou tecnológicos suficientes para elevar a qualidade do ensino.

0 autor também dá destaque ao argumento de que as reformas podem não ser motivadas pelo desejo de aumentar a produtividade da Educação, mas pela necessidade de limitar a responsabilidade financeira e administrativa do Governo Central, 0 que se busca evidenciar neste estudo apontando para os fatores externos e internos que possibilitaram o traçado do novo perfil de Estado no Brasil.

Silva Júnior (2004) registra que, na polêmica existente sobre municipalização do ensino, defensores e opositores reconhecem a tendência presente na organização legal da educação brasileira no sentido de atribuir ao município responsabilidade pela educação básica, ao menos a fundamental e a infantil. Neste quadro, ao assumir sua responsabilidade e realizar suas atribuições, o município, a partir da implementação do dispositivo legal de gestão democrática, atua sobre lógicas e procedimentos que condicionam a administração municipal; deste modo, o autor (SILVA JÚNIOR, 2004) considera que a institucionalização de práticas participativas importa conhecer o que deve ser feito, o como deve ser feito e o que pode ser feito e que a participação é um principio orientador de uma administração democrática.

No entanto, Silva Júnior (2004) assevera que o processo de municipalização das políticas educacionais em realização no Brasil tem conduzido a Educação ao atendimento do mercado, por conseguinte, ao atendimento às políticas neoliberal-capitalistas, recebendo, de bom grado, os efeitos da globalização, pois a ciência ganhou novo papel, o de precisão e controle. Nesta perspectiva, o autor faz entender que a ciência redunda, hoje, em mercadoria e fator de fragmentação da sociedade civil e o individualismo impera na formação do indivíduo.

Em Mendonça (2001), o patrimonialismo aponta-se no Estado como sendo limite à gestão democrática do ensino público e, nesse diapasão, da política de municipalização, pois, se remetendo à idéia weberiana de burocracia, analisa que esta é entendida 
no Estado patrimonialista apenas como sendo espelho de procedimentos formais, o que viabiliza a gestão autocrática e autoritária com alteração constante das políticas públicas ao 'paladar' das conveniências personalísticas dotadas de amparo clientelístico; logo, o patrimonialismo constitui em si a terra seca e infértil de um tipo de Estado que inibe a germinação das sementes da participação, a qual é pilar da democracia. Caberia, aqui, uma reflexão sobre o modelo patrimonial do Estado brasileiro.

Nessa perspectiva, segundo Mendonça (2000), a reflexão sobre a gestão democrática do ensino público tem em conta o grau de centralização dos sistemas de ensino, que gera um papel periférico para as escolas. Pomos em foco, pois, que a descentralização, princípio da organização político-administrativa estabelecido pela Constituição Federal (BRASIL, 1988), e fundamento do princípio de autonomia dos entes municipais, não é democratizadora por si, podendo ser um instrumento de ação autoritária e não constituir uma prática associada à democracia e à participação.

A municipalização do ensino fundamental com a descentralização de atribuições dos Estados para os Municipios tem sido alvo de análise em produção acadêmica e, neste texto, destaca-se a contribuição de Martins (2004) que, em estudo de caso no Estado de São Paulo, situa os limites a serem superados, quais sejam: a questão da diversidade de formação cultural e profissional entre os servidores de cada qual das redes; a cultura institucional sedimentada em cada servidor ao longo de seu tempo de casa; a da diferença salarial; a diferenciada jornada diária de trabalho pelo número de matrículas e o aproveitamento dos servidores pelo ente municipal que culmina, por vezes, em desvio de função. Há que se ressaltar que o processo de municipalização do ensino ocorreu em parte considerável dos estados da federação ao longo do final dos anos 1990 e início do século XXI.

\section{Algumas considerações em busca de novos pontos de partida}

A cidadania e a educação guardam entre si uma relação viva de forças e potencialização recíproca. Para tanto, cumpre observar que Marshall (1967), ao analisar o cenário inglês durante o processo de garantia dos direitos civis, políticos e sociais, já reconhecia a potencialização da cidadania apontando como fator a Educação, que assim transformaria os indivíduos em lordes ${ }^{3}$.

Neste sentido, a análise das políticas educacionais deve ser uma análise contínua por parte dos estudiosos e do próprio Estado, pois somente com o avanço nesse campo político-social é que se pode favorecer um indivíduo excluído no sentido do exercício de sua cidadania, a partir de sua participação social e autonomia.

3 Os lordes seriam os cavalheiros, expressões substituídas por Marshall (1967) pelo termo 'civilizados'. A democracia é condicionada ao fato de que as pessoas se lapidem politicamente, e a lapidação do indivíduo somente se promove pelo acesso à educação que, por sua vez, autonomiza o indivíduo e faz deste um lorde (MARSHALL, A. apud MARSHALL, T. H., 1967). 
Ante as variáveis analisadas, o presente trabalho propugna pela discussão acerca dos reflexos, limites e potencialidades, das políticas de municipalização. Entende-se que, deste modo, o pensamento pode ser construido, as falhas suprimidas e os avanços festejados.

Se defender as politicas de municipalização da forma que têm sido procedidas, mostra-se ato leviano ao não se levar em consideração as características locais que permeiam o Estado brasileiro, como o patrimonialismo, a diversidade cultural e econômica e mesmo a visão de minimização da política de Educação no que tange às dotações orçamentárias e apoio técnico e de pessoal, mas, manter o papel acusatório em torno das mesmas políticas seria, de certo, inconsequente por ir de encontro à gestão democrática, um avanço no histórico das Constituições nacionais outorgadas e promulgadas ao longo do processo evolutivo de formação dos direitos sociais, civis e políticos no Brasil.

A defesa dialética do levantamento da questão guarda relevância e pertinência com a revisão de valores por parte do Estado e da própria sociedade civil: um Estado de muitas garantias, entretanto hipertrofiado no campo axiológico das políticas e programas governamentais, ao mesmo tempo em que validado e legitimado por uma sociedade civil fragmentada, individualista e orientada pelo sistema neoliberalcapitalista de mercado, que reduz a postura do cidadão a de consumidor passivo. Assim, o que se crê necessário é que o tema seja posto à mesa de debates e analisado considerando os limites e potencialidades locais de cada ente federativo integrante desse processo.

Ao se considerar o desenvolvimento do Brasil à luz da democracia, há que se ter em conta o número de instâncias em que sejam asseguradas a participação dos cidadãos e a autonomia das instituições. Assim, a gestão democrática do sistema de ensino público, quer no poder executivo municipal (Secretaria de Educação), quer nas escolas, configura o perfil de regime democrático. A organização jurídico politica do Estado democrático de direito se fortalece com a municipalização do sistema de ensino, desde que a descentralização não se efetive como desvanecimento das responsabilidades atribuídas aos demais entes federativos. 


\section{Referências}

BAUMAN, Z. Depois da Nação-Estado, o quê? In: Globalização: as conseqüências humanas. Tradução Marcus Penchel. Rio de Janeiro: Zahar, 1999. p. 63-84.

BRASIL. Constituição (1988). Constituição da República Federativa do Brasil, de 5 de outubro de 1988. Brasília, DF: Senado Federal, 1988.

. Decreto n. ${ }^{\circ} 2.264$, de 27 de junho de 1997. Regulamenta a Lei no 9.424, de 24 de dezembro de 1996, no âmbito federal, e determina outras providências. Diário Oficial [da] República Federativa do Brasil, Brasília, DF, 28 jun. 1997.

. Emenda Constitucional $n^{\circ} 14$, de 12 de setembro de 1996. Modifica os arts. 34, 208, 211 e 212 da Constituição Federal e dá nova redação ao art. 60 do Ato das Disposições constitucionais Transitórias. Diário Oficial [da] República Federativa do Brasil, Brasilia, DF, 13 set. 1996a.

. Lei $n^{0}$. 5.692, de 11 de agosto de 1971. Fixa Diretrizes e Bases para $1^{\circ} \mathrm{e}$ $2^{\circ}$ graus, e dá outras providências. Diário Oficial [da] República Federativa do Brasil, Brasilia, DF, 12 ago. 1971.

BRASIL. Lei no. 9.394, de 20 de dezembro de 1996. Dispõe sobre as Diretrizes e Bases da Educação Nacional. Diário Oficial [da] República Federativa do Brasil, Brasilia, DF, 23 dez. 1996b.

Lei ñ. 9.424, de 24 de dezembro de 1996. Dispõe sobre o Fundo de Manutenção e Desenvolvimento do Ensino Fundamental e de Valorização do Magistério, na forma prevista no art. $60, \S 7^{\circ}$, do Ato das Disposições Constitucionais Transitórias, e dá outras providências. Diário Oficial [da] República Federativa do Brasil, Brasília, DF, 26 dez. 1996c.

BRITO, V. L. F. A. 0 público, o privado e as políticas educacionais. In: OLIVEIRA, D.; DUARTE, M. R. T. (Org.). Política e trabalho na escola. Belo Horizonte: Autêntica, 2003. v. 1, p. 129-139.

CARNOY, M. A educação na América Latina está preparando sua força de trabalho para as economias do século XXI? Brasilia, DF: UNESCO Brasil, 2004.

. Mundialização e reforma da educação: o que os planejadores devem saber. Tradução de Guilherme João de Freitas Teixeira. Brasília, DF: Unesco Brasil, IIPE, 2003.

CURY, C. R. J. Federalismo politico e educacional. In: FERREIRA, N. S. C. (Org.). Políticas públicas de gestão da educação: polêmicas, fundamentos e análise. Brasilia: Liber Livro Ed., 2006. p. 113-127. 
DAVIES, N. Municipalização do ensino: democratização ou privatização? In:

Contexto e Educação, ljui, RS, v. 7, n. 25, p. 31-44, 1992.

FERREIRA, N. S. C. Gestão democrática da educação para uma formação humana: conceitos e possibilidades. Em Aberto, Brasília, DF, v. 17, n.72, p. 167-177, fev./ jun. 2000.

GUIMARÃES, C. S. Participação sociopolitica e governança democrática: o papel dos Conselhos Municipais de Educação na gestão e implementação da política educacional. In: REUNIÃO ANUAL ANPED, 30., 2006, Caxambu; GT ESTADO E POLÍTICA EDUCACIONAL, 5., 2006, Caxambu. Trabalhos apresentados...

Caxambu: ANPED, 2006. Disponível em: <www.anped.org.br/reunioes/30ra/ trabalhos/GT05-3032-Int.pdf >. Acesso em: 22 jul. 2011.

LASALLE, F. A essência da Constituição. Prefácio de Aurélio Wander Bastos. Rio de Janeiro: Líber Júris, 1985.

LIBÂNEO, J. C.; OLIVEIRA, J. F.; TOSCHI, M. Elementos para uma análise críticocompreensiva das políticas educacionais: aspectos sociopolíticos e históricos. In: . Educação escolar: políticas, estrutura e organização. São Paulo: Cortez, 2003. p. 129-149.

MARSHALL, T. H. Cidadania, classe social e status. In: Cidadania e classe social. Rio de Janeiro: Zahar, 1967. p. 57-114.

MARTINS, A. M. A municipalização do Ensino: algumas questões sobre o poder local.

Revista Iberoamericana de Educación, Madrid, v. 33, n. 2, p. 9-17, 2004.

MENDONÇA, E. F. Estado patrimonial e gestão democrática do ensino público no Brasil. Educação \&t Sociedade, Campinas, SP, ano 22, n. 75, p. 84-108, ago. 2001.

MENDONÇA, E. F. Gestão democrática do ensino: luta e institucionalização. In: - A regra e o jogo: democracia e patrimonialismo na educação brasileira. Campinas, SP: Edições Lapplane, 2000.

MORAES, A. Direito constitucional. São Paulo: Atlas, 2007.

NOGUEIRA, M. A. Entre o local e o global. In: MARTINS, A. M.; OLIVEIRA, C.; BUENO, M. S. S. (Org.). Descentralização do Estado e municipalização do ensino: problemas e perspectivas. Rio de Janeiro: DPCA, 2004. p. 13-28. 
ORGANIZACIÓN DE LAS NACIONES UNIDAS. Las conferencias mundiales: formulación de prioridades para el siglo XXI. Nueva York: Departamento de Información Pública de las Naciones Unidas, 1997.

SANDER, B. Política e administração da educação no Brasil: momentos de uma história em construção. In: Políticas públicas e gestão democrática da educação. Brasilia, DF: Liber Livro Ed., 2005. p. 91-115.

SILVA JÚNIOR, J. R. 0 papel político da municipalização educacional na construção de novos traços da sociedade civil na década de 1990. In: MARTINS, A. M.; OLIVEIRA, C.; BUENO, M. S. S. (Org.). Descentralização do Estado e municipalização do ensino: problemas e perspectivas. Rio de Janeiro: DP\&A, 2004. p. $57-83$.

SOBOTTKA, E. A. Por que se faz políticas sociais no Brasil?: notas sobre estratégia de legitimação nos últimos dois governos federais. Civitas: revista de Ciências Sociais, Porto Alegre, RS, v. 6, n. 1, jan.-jun. 2006. p. 79-93.

THERBORN, G. As teorias do Estado e seus desafios no fim de século. In: SADER, E.; GENTILI, P. (Org.). Pós-neoliberalismo II. São Paulo: Vozes, 1999. p. 79-89.

WERLE, F. O. C. O nacional e o local: ingerência e permeabilidade na educação brasileira. Bragança Paulista, SP: Ed. Universidade São Francisco, 2005.

Recebido em: 19/08/2010

Aceito para publicação em: 30/05/2011 